\title{
Analysis of Thermally Induced Changes in Fractured Rock Permeability during Eight Years of Heating and Cooling at the Yucca Mountain Drift Scale Test
}

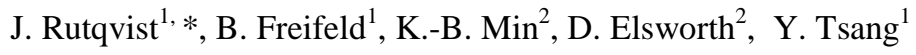 \\ ${ }^{1}$ Earth Sciences Division, Lawrence Berkeley National Laboratory, MS 90-1116, Berkeley, CA 947 20, USA \\ ${ }^{2}$ Department of Energy and Geo-Environmental Engineering, Pennsylvania State University, University Park, \\ PA 16802, USA \\ * Corresponding author. Tel.: +1-510-486-5432, fax.: +1-510-486-5432 \\ E-mail address: Jrutqvist@lbl.gov (J. Rutqvist)
}

\begin{abstract}
We analyzed a data set of thermally induced changes in fractured rock permeability during a four-year heating (up to $200^{\circ} \mathrm{C}$ ) and subsequent four-year cooling of a large volume, partially saturated and highly fractured volcanic tuff at the Yucca Mountain Drift Scale Test, in Nevada, USA. Permeability estimates were derived from about 700 pneumatic (air-injection) tests, taken periodically at 44 packed-off borehole intervals during the heating and cooling cycle from November 1997 through November 2005. We analyzed air-permeability data by numerical modeling of thermally induced stress and moisture movements and their impact on air permeability within the highly fractured rock. Our analysis shows that changes in air permeability during the initial four-year heating period, which were limited to about one order of magnitude, were caused by the combined effects of thermal-mechanically-induced stress on fracture aperture and thermal-hydrologically-induced changes in fracture moisture content. At the end of the subsequent four-year cooling period, air-permeability decreases (to as low as 0.2 of initial) and increases (to as high as 1.8 of initial) were observed. By comparison to the calculated thermo-hydro-elastic model results, we identified these remaining increases or decreases in air permeability as irreversible changes in intrinsic fracture permeability,
\end{abstract}


consistent with either inelastic fracture shear dilation (where permeability increased) or inelastic fracture surface asperity shortening (where permeability decreased). In this paper, we discuss the possibility that such fracture asperity shortening and associated decrease in fracture permeability might be enhanced by dissolution of highly stressed surface asperities over years of elevated stress and temperature.

\section{INTRODUCTION}

Coupled thermal-hydrological-mechanical (THM) processes in geological media must be assessed when evaluating the performance of a geological nuclear waste repository [1]. The heat released by the emplaced waste leads to elevated temperature and changes the stress field in the rock mass for thousands of years. Such elevated temperature and stress lead to changes in hydrogeological properties that can impact the performance of a geological repository, because the flow processes in the vicinity of emplacement tunnels would be altered from what they were initially. Changes in hydrogeological properties may have a bigger impact on the long-term performance if they are permanent (irreversible), in which case they would persist after the temperature has cooled down to ambient. That is, they would affect the entire repository compliance period, which may be as long as a million years.

The Yucca Mountain Drift Scale Test (DST) is a large-scale, multiyear, rock-mass heating experiment designed to study thermally driven coupled processes in fractured rocks by using electrical resistance heaters to simulate the thermal loading that results from the emplacement of radioactive waste, albeit at an accelerated rate. The DST also provides a unique opportunity to study potential irreversible changes in hydrologic rock mass properties that might occur as 
a result of several years of thermal and mechanical loading. The DST, which started in 1997, included a four-year period of forced heating, followed by a four-year period of unforced (natural) cooling. A volume of over $100,000 \mathrm{~m}^{3}$ of highly fractured volcanic tuff was heated, including several-tens-of-thousand of cubic meters heated to above boiling temperature. This massive heating induced strongly coupled thermal-hydrological-mechanical-chemical (THMC) changes that were continuously monitored by thousands of sensors embedded in the fractured rock mass. Of particular interest to this study is the periodic active pneumatic (airinjection) testing used to track changes in air permeability within the variably saturated fracture system around the DST.

Previous coupled THM analyses of the initial four-year heating period (lasting from December 1997 through January 2002) indicated that the observed air-permeability changes were a result of both thermal-mechanical (TM) changes in fracture aperture and thermalhydrological $(\mathrm{TH})$ changes in fracture moisture content $[2,3,4]$. Moreover, those previous analyses indicated that the TM-induced changes in fracture aperture and intrinsic permeability would be mostly reversible. That is, most TM-induced changes in intrinsic permeability occurring during heating would diminish when the temperature cooled to ambient. However, the prediction of reversible behavior was based on analysis of data from the four-year heating period and did not include the newly available data from the subsequent four-year cooling period.

In this study, we analyze thermally induced permeability changes at the DST for both the four-year heating period and the subsequent four-year cooling period. Moreover, whereas the 
previous analyses were focused on permeability evolution in a few selected locations within the rock mass, here we analyze all available air-permeability data. This includes airpermeability data from over 700 pneumatic (air-injection) tests taken in 44 packed-off borehole intervals from November 1997 through November 2005. By analyzing data from the entire heating and cooling cycle, we are here able to identify irreversible changes in intrinsic fracture permeability and discuss the potential mechanisms behind such irreversibility.

\section{THE YUCCA MOUNTAIN DRIFT SCALE TEST}

The DST is located at Yucca Mountain, Nevada, in a side alcove of an underground tunnel, the Exploratory Studies Facility (ESF), at a depth of about $250 \mathrm{~m}$ in partially saturated, highly fractured volcanic tuff (Fig. 1a) [5]. The DST is centered around a drift, denoted the Heated Drift, which is about $50 \mathrm{~m}$ long and $5 \mathrm{~m}$ in diameter. It is located in a highly fractured welded tuff described as Topopah Spring Tuff (Formation), Crystal-Poor (Member), Middle Non Lithophysal (Zone) (Tptpmn), and is one of the units considered for siting the proposed nuclear waste repository at Yucca Mountain.

From a hydrological perspective, the highly fractured welded tuff at the site may be characterized as a partially saturated dual-continuum medium, consisting of interacting fracture and matrix continua. The effective rock-mass permeability at the site of the DST is on the order of $1 \times 10^{-13} \mathrm{~m}^{2}$, dominated by the permeability of the fracture system, whereas the permeability of the rock matrix is on the order of $1 \times 10^{-17} \mathrm{~m}^{2}[2,5]$. The main part of the $11 \%$ total rock-mass porosity is comprised of matrix porosity, with fracture porosity estimated to 
be less than $1 \%$ [6]. At ambient conditions, the matrix pores are about $90 \%$ saturated, whereas the fracture system is considered to be almost completely dry.

From a mechanical perspective, the welded tuff at the site is relatively competent, although intense fracturing substantially reduces rock-mass stiffness and strength. For example, Young's modulus of intact rock determined from laboratory tests ranges from about 30 to 35 GPa, whereas the corresponding in situ deformation modulus of the fractured rock mass has been estimated to be about half of the intact value (i.e., about $15 \mathrm{GPa}$ ) $[2,5]$. Thermal properties of the welded tuff are dominated by those of its matrix, including a thermal conductivity of about 1.7 to $2 \mathrm{~W} / \mathrm{mK}$ (depending on the degree of liquid saturation) and a thermal expansion coefficient of about 8 to 20 microstrain $/{ }^{\circ} \mathrm{C}$ (depending on temperature) [2].

Through extensive fracture mapping at the DST drifts and in the neighboring ESF tunnel, three orthogonal fracture sets have been identified in the Tptpmn unit [7]—a prominent subvertical, NW-SE trending, a less prominent subvertical, NE-SW trending, and a subhorizontal. The average strike of the fractures belonging to the two subvertical fractures sets are approximately parallel and perpendicular to the axis of the Heated Drift (Fig. 1a). In addition, there are randomly oriented fractures that account for about $30 \%$ of the mapped fractures in the Tptpmn unit. The average spacing obtained from line surveys of fractures larger with trace lengths than $1 \mathrm{~m}$ has been estimated to about $0.3 \mathrm{~m}$ [7]. However, alternative detailed-line surveys of small-scale fractures have showed that the majority of fractures in the Tptpmn unit are small-scale fractures with trace length shorter than $1 \mathrm{~m}$; fractures longer than $1 \mathrm{~m}$ accounted for less than $20 \%$ of all fractures. Thus, including small-scale fractures, the 
average fracture spacing is much less than $0.3 \mathrm{~m}$. Moreover, a large number of airpermeability tests conducted in short-interval $(0.3 \mathrm{~m})$ packed-off borehole sections (not part of the air-injection tests analyzed within this study) in the Tptpmn unit show that fluidconducting fractures exist at least every $0.3 \mathrm{~m}$ [8]. This is evidence of an intensively fractured media forming a well-connected network of hydraulic conductive fractures [7].

During the four-year forced heating period, heat was provided by canister heaters meant to simulate radioactive waste packages along a $47.5 \mathrm{~m}$ long section of the Heated Drift, as well as by 50 rod heaters, referred to as "wing heaters," placed into horizontal boreholes extending from, and orthogonal to, the Heated Drift (Figs. 1a and 2a). The wing heaters provided additional heat to the rock mass, simulating the effect of heat from neighboring drifts that would occur at a full-scale nuclear waste repository. During the entire eight-year heating and cooling cycle, the heated drift was isolated from the connecting tunnel through a thermally insulated bulkhead (Figs. 1a and 2a).

Fig. 1b shows the time-evolution of heater power and drift-wall temperature for the entire eight-year DST heating and cooling cycle. The heaters were activated on December 3, 1997. Within three months, the temperature at the drift wall rose to the boiling point (about $96^{\circ} \mathrm{C}$ ) and then continued to rise at a slower rate (Fig. 1b). This slower rate is a function of the energy required to vaporize liquid water as the zone of boiling progressed from the drift wall and several meters into the rock. Towards the end of the four-year heating period, the thermal input was deliberately stepped down by $10 \%$ a few times in order that the maximum drift-wall temperature did not exceed about $200^{\circ} \mathrm{C}$ (Fig. 1b, upper). The forced heating continued for 
approximately four years, until January 14, 2002, when the heaters were turned off. At that time, the boiling isotherm (about $96^{\circ} \mathrm{C}$ ) had extended tens of meters away from the Heated Drift and wing heaters (Fig. 1a). During the subsequent four-year cooling period, the Heated Drift remained isolated from the connecting tunnel through the thermally insulated bulkhead. At the end of the cooling period, the temperature at the drift wall was still significantly elevated (at about $60^{\circ} \mathrm{C}$ ) compared to the initial temperature of $24^{\circ} \mathrm{C}$ (Fig. 1b). The unforced cooling period was formally terminated in June 2006, and monitoring of the rock mass ceased.

Throughout the entire eight years of heating and cooling, passive monitoring and active testing of THMC changes were conducted in the near-field rock mass [5]. The monitoring was conducted through thousands of sensors installed in 147 boreholes around the Heated Drift. Our focus here is on the results of periodic pneumatic (air-injection) testing of permeability. These pneumatic tests were conducted in clusters of $40 \mathrm{~m}$ long boreholes forming vertical fans that bracket the Heated Drift and the wing heaters at three locations (Fig. 2a to d). A string of custom-designed high-temperature packers were installed to divide each of the $40 \mathrm{~m}$ long boreholes typically into three or four isolated zones (or intervals) of about 5 to $10 \mathrm{~m}$ each. After installation of the pneumatic packer strings, baseline air-injection tests were performed in each borehole interval before the heaters were turned on. The pneumatic packers were then left inflated in the boreholes, and air-injection tests were performed typically every three months during the eight-year heating and cooling cycle. 
During each air-injection test, local air permeability was estimated from the steady-state pressure response to a constant-flux air-injection [5]. By repeatedly performing measurements using the same testing configuration and applying the same analysis model, changes in the rock mass response could be temporally resolved with high accuracy over the course of the eight-year DST experiment. However, measurement of air permeability in a humid, high temperature environment is challenging. As temperature increased in the rock mass, many airinjection tests showed responses that were considered anomalous. Most of the unusual behavior was attributed to two-phase processes, such as vapor condensation and evaporation, in which case no meaningful steady-state flow response was obtained [5]. Moreover, as the heating progressed, many of the pneumatic packers failed and deflated under the intense heat. Air-permeability values used in this paper are derived from air-injection tests conducted in intact packer intervals, and from pressure and flow data from which a meaningful steady-state pressure response could be obtained and interpreted.

Fig. 2e shows the results of air-permeability measurements conducted in 44 test intervals over the eight-year heating and cooling cycle. Initially, 46 test intervals were installed. However, for two intervals (77:2 and 77:3), no reliable data could be retrieved during heating and cooling. The results in Fig. 2e are presented as the evolution of a permeability change factor, defined as the ratio of current permeability over initial (preheating) permeability $\left(k / k_{i}\right)$. Taking the available measurements as a whole (without the benefit of the detailed evolution at each and every individual test interval), we can conclude that air-permeability changes remain within about one order of magnitude throughout the entire heating and cooling cycle. At the end of the cooling period, 11 out of the original 46 test intervals remained intact. For those 11 
test intervals, permeability-change factors range from 0.2 to 1.8 of the initial value through the cooling period. Permeability changes remaining at the end of the cooling period are of particular interest to our study, since they may be a result of irreversible (inelastic) changes in intrinsic fracture permeability.

\section{THM MODEL SETUP OF THE DST}

To simulate the coupled THM response of the rock mass to thermal cycling a model approach similar to what was successfully applied in the previous modeling of the initial four-year heating period was followed [2]. The model simulation was conducted in a two-dimensional (plane strain) model in a cross section perpendicular to the axis of the Heated Drift. The simulation was conducted with TOUGH-FLAC, which is a simulator for analysis of multiphase fluid and heat transport coupled with geomechanical deformations [9]. The conceptual model for multiphase fluid flow and heat transport and the approach for calculating stress-induced changes in permeability within the highly fractured rock duplicate those used in the previous modeling of the four-year heating phase [2]. This includes a dualpermeability continuum model, considering important hydraulic interactions between rock matrix and fractures $[10,11]$. Moreover, changes in intrinsic permeability are evaluated from thermal-elastic changes in fracture aperture, caused by changes in stress normal to fractures of the three dominant fracture sets [9].

\subsection{Hydromechanical Model of the Highly Fractured Volcanic Tuff}

The hydromechanical model considers changes in porosity, permeability, and capillarity, in the fractured continua as a result of stress-induced changes in fracture apertures [9]. Changes 
in hydrological properties are calculated using a conceptual model of three orthogonal fracture sets consistent with the three main fracture sets observed at the site (Fig. 3b). The permeability along $\mathrm{x}, \mathrm{y}$, and $\mathrm{z}$ directions are calculated from the aperture, $b$, and spacing, $s$, of fractures belonging to the three orthogonal fracture sets using a parallel-plate fracture flow model $[9,12]$. The current fracture aperture $b$ depends on the current effective normal stress $\sigma_{n}^{\prime}$, according to the following exponential function [14]:

$$
b=b_{r}+b_{m}=b_{r}+b_{\max }\left[\exp \left(\alpha \sigma_{n}\right)\right]
$$

where $b_{r}$ is a residual aperture, $b_{m}$ is a mechanical aperture, $b_{\max }$ is the mechanical aperture corresponding to zero normal stress, and $\alpha$ is a parameter related to the curvature of the function (Fig. 3c). This relationship can also be expressed in terms of an initial aperture, $b_{i}$, and changes in aperture, $\Delta b$, as:

$$
b=b_{i}+\Delta b=b_{i}+b_{\max }\left[\exp \left(\alpha \sigma_{n}\right)-\exp \left(\alpha \sigma_{n i}\right)\right]
$$

where $\sigma_{n i}$ is the initial stress normal to the fractures. In Equations (1) and (2), the engineering sign convention used for effective normal stress, which implies that tensile stress is positive and compressive stress is negative. In this conceptual model we assume that the aperture uniform within the fractures, whereas in the nature it could be highly variable both within a fracture and between fractures.

\subsection{Material Properties and Initial and Boundary Conditions}

Table 1 presents material properties we use to model the Tptpmn unit. Hydrological properties include water-retention curves and relative permeability functions based on van Genuchten [15] and Corey [16] models. Mechanical properties include a fractured rock-mass 
deformation modulus of $14.77 \mathrm{GPa}$ and a temperature-dependent thermal expansion coefficient [2].

The parameters $b_{\max }, \alpha$ and $b_{r}$ defining the stress-aperture relationship in Equations (1) and (2) need to be calibrated against site-specific field measurements of permeability changes during stress changes. The parameters defining the in situ stress-aperture relationship can generally not be determined from small-scale laboratory experiments, because of scale dependency and/or sampling biases [17]. The investigation and calibration of the stressaperture relationship is described in detail in Section 4.2 below, since it is an important part of our analysis and involves detailed interpretation of the above mentioned air-injection tests. Nevertheless, the final calibrated parameters valid for the applied conceptual stress-versuspermeability model, with initial permeability of $1 \times 10^{-13} \mathrm{~m}^{2}$ and fracture spacing of $0.23 \mathrm{~m}$, are $b_{\text {max }}=37.6 \mu \mathrm{m}, \alpha=0.07 \mathrm{MPa}^{-1}$ and $b_{r}=22.1 \mu \mathrm{m}$. These are the basic calibrated stressaperture parameters applied when deriving model results presented in this paper.

Initial and boundary conditions are presented in Table 2 and 3 (see also Fig. 3a). The initial stress, temperature, and phase saturations shown in Table 2 are the results of an initial steadystate simulation using the boundary conditions shown in Table 3. At Yucca Mountain, vertical stress resulting from the weight of the overlying rock is the maximum principal stress, whereas the two horizontal principal stresses are estimated to be about half the magnitude of the vertical stress. At ambient (initial) conditions, the matrix is almost fully saturated with water, whereas fractures are considered almost dry (as a result of matrix water imbibition). 


\section{MODELING SEQUENCE AND RESULTS}

The model simulation in this study is focused on the analysis of thermally induced changes in air permeability, meaning that we need to make an accurate simulation of the evolution of temperature, stress, and moisture movements within the fractured rock system. We first studied the temperature evolution to ensure that simulated temperature evolution and distribution closely matched field observations (Section 4.1). We then studied the thermally induced changes in stress and fracture moisture content (liquid saturation) and sampled the evolution of stress and gas saturation at each air-injection interval to be used for calculating the air-permeability evolution (Section 4.2). We calibrated the stress-aperture relationship by matching the evolution of calculated and measured changes in air permeability in each airinjection interval during the heating and cooling cycle (Section 4.3). Finally, we conducted a detailed comparison between the calculated permeability evolution using our calibrated model and the measured permeability evolution, and we identified irreversible changes in permeability (Sections 4.4 and 4.5).

\subsection{Analysis of Temperature}

Similar to the previous modeling of the initial four-year heating period, we had to consider heat loss through the bulkhead located between the Heated Drift and the connecting drift system [2]. Further, for an accurate modeling of the temperature evolution during the entire eight-year heating and cooling cycle in our simplified two-dimensional analysis, it was also necessary to consider out-of-plane heat loss into the surrounding rock mass. Fig. 4a compares

evolution of measured and calculated drift-wall temperature with and without consideration of 
out-of-plane heat loss. Fig. 4b depicts temperature profiles along a vertical borehole extending from the top of the drift for the best-match solution. The best match was obtained with a heatloss coefficient of $0.075 \mathrm{~W} / \mathrm{K}-\mathrm{m}^{2}$ for heat loss thorough the bulkhead and $0.005 \mathrm{~W} / \mathrm{K}-\mathrm{m}^{2}$ for out-of-plane heat loss into the rock.

Fig. 5 presents calculated temperature contours at the end of the four-year heating period and at the end of the subsequent four-year cooling period. At the end of the four-year heating period, the maximum temperature near the drift wall and wing heaters is about $200^{\circ} \mathrm{C}$, and the zone of above-boiling temperature extends as much as $10 \mathrm{~m}$ above and below the center of the drift and $20 \mathrm{~m}$ laterally (Fig. 5a). At the end of the cooling period, the temperature is still significantly elevated, with a temperature above $60^{\circ} \mathrm{C}$ near the drift and a zone of above $40^{\circ} \mathrm{C}$ extending to a distance of more than $30 \mathrm{~m}$ from the center of the drift (Fig. 5b). Given the good match between the calculated and measured temperature, the calculated temperature distribution shown in Figure 5 should be representative of the in situ temperature at the DST.

\subsection{Calculated Thermally-Induced Stress and Moisture Movements}

The coupled THM analysis shows that the high temperature near the drift and the wing heaters causes strong TM and TH responses in the form of thermally induced stress and moisture movements (Fig. 6 and 7). In the field, thermally induced changes in stress and moisture content will change the amount of fracture void space available to airflow, which in turn should be reflected in the measured air permeability. In regions of increased compressive stress, fractures will tend to close, resulting in a reduced void space and hence a reduced air 
permeability. Moreover, in regions with increased moisture content (increased liquid saturation) in fractures, the nonwetting void space available for gas flow would be reduced, also resulting in reduced air permeability.

Fig. 6 shows how TH-induced processes affect moisture movement and liquid saturation within the fracture system. During the heating period, high temperature induces evaporation of liquid matrix water and drying near the heat source. Vaporized water is transported as vapor away from the heat source in the permeable fracture system, toward cooler regions, where it is condensed to liquid water (Fig. 6a, dark zone). As a result, a dryout zone is formed near the heat source, and a condensation zone moves progressively away from the heat source. At the end of the four-year cooling period, the previously condensed water in the fracture system has either drained by gravity or been imbibed into the matrix. The dryout zone is rewetted by capillary suction, but in a zone around the Heated Drift and wing heaters the fracture system still remains slightly dryer than the initial preheating conditions (Fig. 6b).

Fig. 7 shows how TM-induced processes affect the stress field and their impact on fracture aperture. The high temperature gives rise to thermal expansion of the rock matrix, with associated thermally induced stress changes. At the end of the four-year heating period, the maximum horizontal stress has increased by up to about $20 \mathrm{MPa}$ near the drift wall and wing heaters. A zone of increased compression has extended to cover an area that includes all airinjection test intervals (compare Fig. 7a to borehole locations in Fig. 2). During the four-year cooling period, the thermal stresses decrease with the decreasing temperature and with the loss of thermal gradient. 


\subsection{Analysis of Thermally-Induced Changes in Air Permeability and Model Calibration}

In this section, we present an analysis of thermally induced changes in air permeability as well as calibration of the stress-aperture relationship used for modeling stress-induced changes in intrinsic permeability. The calibration requires appropriate models for evaluating TM and TH-induced changes in air permeability at each air-injection test interval and a careful analysis and comparison of calculated and measured permeability changes. Moreover, to calibrate the stress-aperture relationship, we must distinguish between air-permeability changes caused by TM-induced changes in stress from $\mathrm{TH}$-induced changes in moisture content.

\subsubsection{Model for evaluating TM-induced changes in air permeability}

In this model calibration, we assume that the measured air-permeability changes evaluated from the air-injection tests are controlled by the aperture and moisture changes in the prominent NW striking subvertical fracture set. Thus, we compared the measured permeability change factor to changes in permeability within the NW-striking fractures set. In the previous published study analyzing the DST heating period, alternative models were applied in which the measured permeability was compared to calculated changes in geometric mean of anisotropic permeability changes, thus a calculated value equally affected by permeability changes in all three orthogonal fracture sets. However, when analyzing the entire heating and cooling period, we found that the field data can be better matched by permeability changes in the NW-striking fracture set. This finding is reasonable since fractures within the 
NW-striking subvertical fracture set strike approximately perpendicular to the subhorizontal monitoring borholes, which implies that fractures from this set are most likely to be hydraulically connected to the boreholes. However, we recognize that it is also possible that fractures other than those belonging to the NW-striking fracture set could intersect and significantly impact the air-injection response.

Using Equation (2) and the cubic law of the parallel-plate flow model [12], the permeability change factor along the NW striking fracture set may be calculated as:

$$
F_{k}^{T M}=F_{k}(\Delta \sigma)=\frac{k\left(\sigma_{x}\right)}{k\left(\sigma_{x i}\right)}=\left[\frac{b_{i}+b_{\max }\left(\exp \left(\alpha \sigma_{x}\right)-\exp \left(\alpha \sigma_{x i}\right)\right)}{b_{i}}\right]^{3}
$$

where $\sigma_{x}$ and $\sigma_{x \mathrm{i}}$ is the current and initial stress in x-direction (i.e., current and initial normal stress $\sigma_{n}$ and $\sigma_{n \mathrm{i}}$ across the NW striking fracture set). The initial aperture $\mathrm{b}_{\mathrm{i}}$ depends on the initial intrinsic permeability $\mathrm{k}_{\mathrm{i}}$ as:

$$
b_{i}=\sqrt[3]{k_{i} 12 s}
$$

where $\mathrm{s}$ is the fracture spacing. Note that in Equation (3), only two of the three parameters defining the stress-aperture function, $b_{\max }$ and $\alpha$, are present, whereas the residual aperture $b_{r}$ is given by

$$
b_{r}=b_{i}-b_{m}=b_{i}-b_{\text {max }} \exp \left(\alpha \sigma_{x i}\right)
$$

Thus, for an initial aperture given from the initial intrinsic permeability in Equation (4), we only have to calibrate two of the three parameters defining the stress-aperture function. However, whereas the permeability in the rock mass surrounding the DST is on the order of 
$1 \times 10^{-13} \mathrm{~m}^{2}$, the initial permeability measured in each of the 44 air-injection test intervals ranges from $7.3 \times 10^{-15}$ to $9.0 \times 10^{-13} \mathrm{~m}^{2}$. Assuming the fracture spacing to be 0.23 , this range of permeability results in an equivalent initial aperture ranging from about 27 to $104 \mu \mathrm{m}$, according to Equation (4). Although we used the initial homogeneous permeability of $1 \times 10^{-13}$ $\mathrm{m}^{2}$ in our simulation of thermally induced changes in stress and moisture content, we believe that it is important to consider the actual local permeability, and local estimated initial aperture, when interpreting the evolution of permeability in each air-injection interval. In effect, if we are using Equation (2) and the same calibrated values of $b_{\max }$ and $\alpha$ in all test intervals, then a different initial permeability and initial aperture will result in a different residual aperture for fractures intersecting each borehole interval. A different approach to scaling the fracture hydromechanical properties with initial permeability was derived by Liu et al. [18]. They used the same exponential stress-aperture function as in Equation (1), but defined a dimensionless parameter $R_{b}$ as:

$$
R_{b}=\frac{b_{r}}{b_{\max }}
$$

Equation (3) can then be rewritten in the following form:

$$
F_{k}^{T M}=F_{k}(\Delta \sigma)=\frac{k\left(\sigma_{x}\right)}{k\left(\sigma_{x i}\right)}=\left[\frac{R_{b}+\exp \left(\alpha \sigma_{n}\right)}{R_{b}+\exp \left(\alpha \sigma_{n i}\right)}\right]^{3}
$$

Note that the permeability change factor defined in Equation (7) is independent of initial permeability. This is achieved by scaling $b_{r}$ and $b_{\max }$ proportionally with initial permeability, keeping the parameter $R_{b}$ constant. Such scaling would be consistent with a concept that the initial fracture permeability at a certain normal stress would be dependent on the roughness of the fracture surfaces. A rough fracture would have a larger initial aperture than a smooth 
fracture; consistently, a rough fracture would have larger $b_{\max }$ and $b_{r}$ than a smooth fracture. Equation (7) is the basic function used to evaluate TM-induced changes in intrinsic fracture permeability and its impact on air permeability at each air-injection test interval.

\subsubsection{Model for evaluating TH-induced changes in air permeability}

In this study, consistent with current dual-permeability models of the highly fractured welded tuff at Yucca Mountain, the relative permeability for gas flow in fractures is modeled according to the commonly applied Corey [16] model:

$$
k_{r g}=(1-\hat{S})^{2}\left(1-\hat{S}^{2}\right)
$$

where $\hat{S}$ is an effective saturation, defined as

$$
\hat{S}=\left(S_{l}-S_{l r}\right) /\left(1-S_{l r}-S_{g r}\right)
$$

where $S_{l}, S_{l r}$ and $S_{l s}$ are (respectively) current, residual, and saturated liquid-saturation values, and $S_{g r}$ is residual gas saturation. In this study, $S_{l r} \approx 0.0$ and $S_{g r}=0$ for the fracture continuum

(Table 1). With these parameters, $\hat{S}=S_{l}$ and the permeability change factor in terms of gas relative permeability is calculated as a function of liquid saturation, according to:

$$
F_{k}^{T H}=F_{k r g}\left(\Delta S_{l}\right)=\frac{k_{r}\left(S_{l}\right)}{k_{r}\left(S_{l i}\right)}=\frac{\left(1-S_{l}\right)^{2}\left(1-S_{l}^{2}\right)}{\left(1-S_{l i}\right)^{2}\left(1-S_{l i}^{2}\right)}
$$

Equation (10) is the basic function used to evaluate $\mathrm{TH}$-induced changes in gas relative permeability and their affect on air permeability at each air-injection test interval. 


\subsubsection{Model calibration of stress-aperture function}

The model calibration was conducted by simulating the entire sequence of four-year heating and subsequent four-year cooling, using the basic material parameters in Table 1 and comparing calculated and measured permeability evolution in each air-injection interval. We sampled the calculated evolution of stress and gas saturation at the midpoint of each airinjection interval, and applied Equations (7) and (10) to calculate the evolution of TMinduced changes in intrinsic permeability and $\mathrm{TH}$-induced changes in gas relative permeability. The total permeability change factor caused by the combined effects of changes in TM- and TH-induced changes was calculated as:

$$
F_{k}\left(\Delta \sigma_{x}, \Delta S_{l}\right)=F_{k}\left(\Delta \sigma_{x}\right) \cdot F_{k r g}\left(\Delta S_{l}\right)
$$

or

$$
F_{k}^{T H M}=F_{k}^{T M} \cdot F_{k}^{T H}
$$

By comparing the measured and calculated permeability change factor for the entire eightyear cycle and for different regions around the heated drift, we could distinguish between TM- and TH-induced changes in air permeability. For example, along boreholes far above the Heated Drift, the measured air permeability changes are caused by TM-induced changes, without interference from TH-induced changes. Using this technique, we found the "best" overall match for $R_{b}=0.59$ and $\alpha=0.07 \mathrm{MPa}^{-1}$. However, when including data from all 700 air-injection tests and the evolution of permeability change factor in 44 test intervals, we also found it impossible to obtain a simultaneously perfect match between calculated and measured permeability at all test intervals. We could only match the general trend of 
evolution of permeability (e.g., matching the regions of increase or decrease in permeability and average magnitudes of the permeability change).

For the initial homogeneous permeability of $1 \times 10^{-13} \mathrm{~m}^{2}$ and fracture spacing of $0.23 \mathrm{~m}$, the calibrated values $R_{b}=0.59$ and $\alpha=0.07 \mathrm{MPa}^{-1}$ would correspond to the basic stress-aperture parameters of $b_{i}=51.7 \mu \mathrm{m}, b_{\max }=37.6 \mu \mathrm{m}, \alpha=0.07 \mathrm{MPa}^{-1}$ and $b_{r}=22.1 \mu \mathrm{m}$ in Equations (1) and (2). However, these numbers should be considered fictive calibration parameters, valid specifically for the conceptual model of highly fractured media with equal uniform spacing $0.23 \mathrm{~m}$ and with all fractures having identical properties. Consider a case in which the permeability responses would be dominated by one wide-open fracture in a $10 \mathrm{~m}$ long airinjection interval. For $R_{b}=0.59$ and $\alpha=0.07 \mathrm{MPa}^{-1}$, the equivalent aperture values in such a

case would increase by a factor $\sqrt[3]{10 / 0.23}=3.5$, leading to $b_{i}=155.1 \mu \mathrm{m}, b_{\max }=131.6 \mu \mathrm{m}, \alpha$ $=0.07 \mathrm{MPa}^{-1}$ and $b_{r}=77.2 \mu \mathrm{m}$. However, by using the dimensionless parameter $R_{b}$, we end up with a permeability change factor that is independent of initial permeability and fracture spacing, which is very convenient for model calibration in a heterogeneous rock mass.

\subsection{Comparison of Calculated and Measured Air Permeability for Calibrated Model}

In Fig. 8, we present the measured and calculated air permeability for all 44 air-injection test intervals at the DST. (As mentioned in Section 2, for two of the 46 test intervals, 77:2 and 77:3, no reliable permeability data could be retrieved, and hence these are not included in Fig. 8.) The locations of the test intervals can also be found in Fig. 2 and the initial (baseline) permeability measured in each test interval and length of each test interval are given in Fig. 8. 
The measured results (square symbols) are compared to calculated TM-induced changes (solid line), as well as to the calculated total, or THM-induced, change in air permeability, which includes the combined effects of TM- and TH-induced changes (dashed line). Overall, Fig. 8 shows that the general trends in the evolution of measured permeability (e.g., increases or decreases) are well captured by the model at most test intervals, although the measured data are scattered at several intervals, and there are systematic deviations between measured and calculated data at some intervals. Some deviations in the measured and calculated responses are expected, considering the existence of local heterogeneities that are not accounted for in the numerical model. Moreover, deviations between measured and calculated permeability values appear to increase during the cooling period. Deviations during the cooling period might be a result of inelastic changes and will be discussed in detail in Section 5 below.

At several air-permeability test intervals located close to the heat source, the results indicate a significant signature of TH-induced change in permeability, in addition to the prominent TMinduced changes. This is most evident at 76:3, 76:4, 186:3, and 186:4, and also (somewhat less prominently) indicated at 59:4, 58:2, and 58:3. For example, in interval 76:4, the permeability first decreases as a result of the superimposed effect of increasing stress and decreasing gas permeability (due to wetting), to reach a minimum of $\mathrm{k} / \mathrm{k}_{\mathrm{i}} \approx 0.1$ at about 2 years (Figure 9a). Thereafter, the modeling shows that some of the reduced permeability recovers as a result of drying of the previously wetted fractures and stabilizes at $\mathrm{k} / \mathrm{k}_{\mathrm{i}} \approx 0.5$. The temporary wetting and subsequent drying is a result of the condensation zone shown in Figure 6a, which progressively moves outward and successively crosses several air-injection 
intervals. The remaining $\mathrm{k} / \mathrm{k}_{\mathrm{i}} \approx 0.5$, at about 4 years, is caused by the elevated horizontal stress that keeps the vertical fractures compressed to an aperture smaller than its initial value.

There is a consistent rapid reduction in air permeability for measurement points located below the Heated Drift (Intervals 60:1, 60:2, 60:3, 60:4, 78:3, 78:4, 186:2). The model shows that this rapid reduction in permeability can be attributed to superimposed TM- and TH-induced changes. As shown in Figure 6a, the rapid TH-induced permeability reduction in this region is caused by increased moisture from local condensation, which is amplified by gravity-driven liquid flow from overlying condensation zones. Unfortunately, as these are the zones in closest proximity to the wing heaters, the interpretation of air-injection responses became problematic because of two-phase processes. Furthermore, the highly elevated temperatures led to failures in the pneumatic packers, eliminating any possibility of collecting addition data within this region.

At some air-permeability test intervals, the model indicates that the observed changes in air permeability are caused entirely by stress-induced changes (e.g., most intervals in boreholes 57, 74 and 185). These test intervals are located far above the Heated Drift, away from the maximum extent of the dryout and wetting zones. At such a distance from the heat source, the fractures stay dry, at the ambient liquid saturation of about 9\%. For test intervals in these boreholes, we may compare calculated and measured TM-induced changes in permeability without interference for TH-induced changes. For example, in interval 57:1, the model shows that the permeability slowly decreases with increasing compressive horizontal stress, to reach a minimum of $\mathrm{k} / \mathrm{k}_{\mathrm{i}} \approx 0.6$ at the end of the four-year heating period (Figure $9 \mathrm{~b}$ ). Thereafter, as 
the rock mass cools down, the compressive stresses are reduced and the permeability recovers to reach a $\mathrm{k} / \mathrm{k}_{\mathrm{i}} \approx 0.8$ at the end of the four-year cooling period. Thus, the remaining permeability reduction by a factor $\mathrm{k} / \mathrm{k}_{\mathrm{i}} \approx 0.8$ is attributed to the remaining thermal stress keeping the fractures slightly compressed as the temperature is still elevated above ambient conditions.

Fig. 10 presents three composite scatter-plots that include all of the more than 700 airpermeability measurements. In Fig. 10a and 10b we show how stress and saturation correlates with permeability change. Fig. 10a shows calculated fracture normal stress versus measured and calculated permeability change factors caused by stress changes, $F_{k}^{T M}$. The figure indicates that the measured permeability change factors generally correlate with the calculated stress changes. However, the calculated permeability change factor caused by stress change, $F_{k}^{T M}$, is somewhat higher than the average of the measured permeability change (A larger portion of the measured values are located to the left rather than to the right of the line of calculated values.). Similarly, Figure $10 \mathrm{~b}$ shows a general correlation between the measured permeability change factor and calculated gas saturation. However, on average, the calculated permeability change factor caused by changes in gas saturation, $F_{k}^{T H}$, is higher than the average of measured values, especially at high gas saturations (dry fractures). Thus, Fig. 10a and 10b illustrate that we need to consider both TM- and TH-induced changes to find a good overall match between the measured and calculated evolution in air permeability. 
Figure $10 \mathrm{c}$ shows a comparison of the measured, $F_{k}^{\text {Meas }}$, versus calculated, $F_{k}^{\text {THM }}$, permeability change factors, in which the calculated included both TM- and TH-induced effects on air permeability. Again, the figure shows that the model captures the "average" behavior reasonable well, although there are many individual points deviating from average behavior. Many of these deviations between the calculated and measured permeability change factor occurred during the cooling period and may be the results of inelastic processes, as discussed in Section 5 below.

\subsection{Identification of Irreversible Changes after Cooling}

At the end of the heating phase, the measured permeability decreased in all but a few measurement intervals. During the subsequent cooling phase, the permeability at many intervals began to recover. This is consistent with the calculated thermal-hydro-elastic response, which shows that the decreasing temperature during the cooling period results in a reduction of thermal stresses acting across fractures, which leads to fracture reopening. Unfortunately, air-injection testing for the entire eight-year heating and cooling cycle could only be completed in 11 out of 44 test intervals. Those 11 intervals are located at a distance of 10 to $15 \mathrm{~m}$ from the heat source, where moisture conditions do not change significantly and where the stress and temperature changes are moderate. A composite plot showing the time evolution of measured and calculated permeability changes in those 11 intervals is shown in Figure 11. (Detailed comparison for each interval can be found in Figure 8.) Figure 11 shows that the calculated thermo-hydro-elastic solution leads to a minimum permeability at the end of the heating period and a subsequent recovery during cooling, ending at a permeability 
change factor of about 0.7 to 0.8 . The measured evolution of permeability follows reasonable close to that of the thermo-hydro-elastic solution for 3 out of 11 test intervals $(57: 1,75: 1$, 76:1). An example of an interval in which the measured permeability followed the trends of the calculated thermo-hydro-elastic, solution is 57:1, shown in Figure 10b. However, the measured permeability change factor in 8 out of the 11 intervals deviates significantly from the thermo-hydro-elastic solution indicating irreversible changes in permeability (Figure 11). Five out of 11 intervals $(74: 1,75: 1,57: 1,58: 1,185: 3)$ show irreversible permeability increases, whereas irreversible permeability decreases can be observed in 3 out of 11 intervals $(74: 2,185: 1,186: 1)$

\section{DISCUSSION: CAUSE AND RELEVANCE OF IRREVERSIBLE CHANGES}

In Figure 11, irrecoverable increases in permeability are observed in 5 out of 11 test intervals. From the TM perspective such irreversible increases in permeability may be the result of fracture shear dilation. During the heating and cooling cycle, fractures may have sheared under dilation, leading to a permanent increase in fracture aperture and thereby an irreversible increase in fracture permeability. We investigated the evolution of shear stress and slip potential (i.e., ratio of shear stress to normal stress at each test interval) assuming both vertical fractures and randomly oriented fractures. At some locations, the shear-to-normal stress ratio exceeded 0.6 to 0.8 , indicating that shear slip could be triggered. However, it would be very difficult to predict exactly where and when such an event would occur. For example, the calculated evolution of stress was very similar at intervals $74: 1$ and 57:1, but irreversible 
permeability increase indicated shear slip occurring only at 74:1. Thus, local heterogeneities, such as local fracture orientation and strength may, have played a role here.

In Figure 11, irreversible permeability reduction is observed in 3 out of 11 test intervals. Such permeability reduction (compared to the thermal-hydro-elastic solution) indicates irreversible contraction of the fracture surfaces, which may result from crushing or dissolution of highly stressed surface asperities under years of elevated stress and temperature conditions. Dissolution of surface asperities has been suggested as a mechanism that could explain field and laboratory observations of fracture-permeability decrease during increasing temperature, even under constant normal stress [19]. Pressure solution involves the serial processes of dissolution at highly stressed fracture surface-asperity contacts, the diffusive transport of dissolved mass along the contact boundaries, and ultimately the precipitation of mineral mass on available free fracture faces. In Figure 11, the strongest irreversible decrease is observed in test interval 74:2. At this interval, the initial permeability was relatively small, suggesting that the initial aperture could be small and that the pressure solution and associate mineral precipitation could be detectable even after a few years. However, the observed irreversible permeability decrease in 3 out of 11 test intervals can only be considered as anecdotal evidence of such a process.

It is unfortunate that the permeability measurements in the test intervals experiencing the highest stress (up to $10 \mathrm{MPa}$ ) and the highest temperature (up to $130^{\circ} \mathrm{C}$ )—where the potential for dissolution might be the highest—failed after a few years. The permeability decrease was indeed most substantial in those intervals, but we have no data to indicate whether 
permeability in those test intervals would remain low or whether they would rebound during the cooling of the rock mass. The observed irreversible permeability changes in the 11 intact intervals located 10 to $15 \mathrm{~m}$ from the heat source ranged from 0.2 to 1.8 of the original permeability. Such small and local changes might not be very significant for the performance of a nuclear waste repository. However, they occurred after only a few years and in intervals with only moderately elevated stress and temperature. Moreover, each measurement interval is typically 5 to $10 \mathrm{~m}$ long and is intersected by a large number of fractures of various sizes and apertures. The observed response likely reflect the responses in the most open fractures or the most open channels, which dominated pressure-flow responses during an air-injection test. Permeability in wide-open fractures and channels would be less impacted by chemically mediated dissolution and mineral precipitation. In the longer term, under sustained temperature and stress increases lasting for thousands of years, the chemically mediated changes would be expected to be much stronger.

\section{CONCLUDING REMARKS}

We have analyzed a data set of thermally-induced changes in fractured rock permeability during eight years of heating and cooling of partially-saturated, highly-fractured volcanic tuff at the Yucca Mountain Drift Scale Test, Nevada. We analyzed the permeability data by numerical modeling of thermally induced stress and moisture movements within the highly fractured rock and their impact on air permeability. Based on our analysis, the following conclusions can be made: 
- Much of the observed changes in air permeability at the site can be explained by thermalmechanically-induced changes in fracture aperture as elevated temperature induced thermal stresses around the DST.

- There is also a strong signature of moisture-induced changes in air permeability, especially near the heat source, where drying and condensation under above boiling temperature conditions are significant.

- Permeability changes during the heating phase were limited to about one order of magnitude, and were caused by the combined effects of thermal-mechanically induced changes in fracture aperture and thermal-hydrologically induced changes in fracture moisture content.

- Irreversible permeability changes that significantly deviated from the reversible thermohydro-elastic solution could be identified in 8 of 11 test intervals for which reliable permeability data could be retrieved until the end of the cooling cycle. At these test intervals, which were located in areas of moderately elevated temperature and stress, remaining permeability change factors ranging from 0.2 to 1.8 of their initial value were observed at the end of the cooling period.

- The identified irreversible permeability changes may be attributed to inelastic thermalmechanical processes consistent with either inelastic fracture shear dilation (where 
permeability increases in 5 out of 11 test intervals) or inelastic fracture surface asperity

shortening (where permeability decreases in 3 out of 11 test intervals).

The observed irreversible permeability decrease and indicated inelastic fracture surfaceasperity shortening may be a result of crushing or dissolution of highly stressed fracture surface asperities during years of elevated stress and temperature conditions. However, partly because of the difficulties in measuring air permeability in areas of the highest temperature and stress, the available air-permeability data do not provide conclusive evidence of such a process.

\section{ACKNOWLEDGMENTS}

We are grateful for reviews by Dr. Hui-Hai Liu and Dr. Dan Hawkes of Lawrence Berkeley National Laboratory, which substantially improved this paper. The work was supported by the Office of Civilian Radioactive Waste Management, Office of the Chief Scientist, of the U.S. Department of Energy under Contract No. DE-AC02-05CH11231.

\section{REFERENCES}

[1] Hudson JA, Stephansson O, Andersson J. Guidance on numerical modeling of thermohydro-mechanical coupled processes for performance assessment of radioactive waste repository. Int J Rock Mech Min Sc 2005;42:850-870.

[2] Rutqvist J, Barr D, Datta R, Gens A, Millard M, Olivella S, Tsang CF, Tsang Y. Coupled thermal-hydrological-mechanical analysis of the Yucca Mountain Drift Scale Test comparison of field results to predictions of four different models. Int J Rock Mech Min Sc 2005;42:680-697. 
[3] Hsiung SM, Chowdhury AH, Nataraja MS. Numerical simulation of thermalmechanical processes observed at the drift-scale heater test at Yucca Mountain, Nevada, USA. Int J Rock Mech Min Sc 2005;42:652-666.

[4] Olivella S, Gens A Double structure THM analyses of a heating test in a fractured tuff incorporating intrinsic permeability variations. Int J Rock Mech Min Sc 2005;42:667-679.

[5] Wagner R. Thermal Testing Measurements Report. TDR-MGR-HS-000002 REV00 ICN 00. Las Vegas, Nevada: Bechtel SAIC Company http://www.ocrwm.doe.gov/documents/amr/38630/index.htm.

[6] Freifeld, B.M., Estimation of Fracture Porosity in an unsaturated fractured welded tuff using gas tracer test, Ph.D. dissertation, U.C. Berkeley Fall 2001

[7] Hinds, J.J., Bodvarsson G.S, and Nieder-Westermann. G.H. (2003). Journal of Contaminant Hydrology 2003;62-63:111-132.

[8] Wang J, Cook P, Trautz R, Flexser S, Hu Q, Salve R, Hudson D, Conrad M, Tsang Y, Williams K, Sol, W, Turin J. In-situ field testing of processes ANL-NBS-HS-000005 REV01. Las Vegas, Nevada: Bechtel SAIC Company, 2001.

[9] Rutqvist J, Wu YS, Tsang CF, Bodvarsson G. A Modeling Approach for Analysis of Coupled Multiphase Fluid Flow, Heat Transfer, and Deformation in Fractured Porous Rock Int J Rock Mech Min Sc 2002;39:429-442.

[10] Tsang YW, Birkholzer JT. Predictions and Observations of the Thermal-Hydrological Conditions in the Single Heater Test. Journal of Contaminant Hydrology 1999;38(1-3): 385425 .

[11] Birkholzer JT, Tsang YW. Modeling of thermal-hydrologic processes in a large-scale underground heater test in partially saturated tuff. Water Resources Research 2000;36(6): $1431-1447$.

[12] Witherspoon PA, Wang JSY, Iwai K, Gale JE. Validity of cubic law for fluid flow in a deformable rock fracture. Water Resourc Res 1980;16:1016-1024

[13] Leverett, M.C. 1941. Capillary behavior in porous media. Trans AIME 1941;142: 341-358.

[14] Rutqvist J and Tsang CF. Analysis of thermal-hydrologic-mechanical behavior near an emplacement drift at Yucca Mountain. Journal of Contaminant Hydrology. 2003;62-63:637652.

[15] van Genuchten MT. A closed-form equation for predicting the hydraulic conductivity of unsaturated soils. Soil Sci Soc Am J 1980;44:892-898. 
[16] Corey AT. The interrelation between oil and gas relative permeabilities. Producers Monthly November 1954: 38-41.

[17] Rutqvist J., Stephansson O. The role of hydromechanical coupling in fractured rock engineering. Hydrogeology Journal 2003;11:7-40.

[18] Liu H.H., Rutqvist J., Zhou G. and Bodvarsson G.S. Upscaling of normal stresspermeability relationship for fracture network obeying the fractional levy motion. In: Stephansson O, Hudson JA, Jing L, editors. Coupled T-H-M-C Processes in Geo-Systems: Fundamentals, Modelling, Experiments and Applications. Elsevier Geo-Engineering Book Series, Oxford, 2004;263-268.

[19] Min KB, Rutqvist J, Elsworth D. Chemically- and mechanically-mediated influences on the transport and mechanical characteristics of rock fractures. Submitted for publication. $30 \mathrm{pp}$. 


\section{Tables}

Table 1. Rock properties of the highly fractured welded tuff (Tptpmn unit).

\begin{tabular}{|l|l|}
\hline \multicolumn{1}{|c|}{ Property } & Value \\
\hline \multicolumn{2}{|l|}{ Matrix Hydrologic and Thermal Properties } \\
\hline Permeability & $1.24 \mathrm{E}-17 \mathrm{~m}^{2}$ \\
\hline Porosity & 0.11 \\
\hline Van Genuchten, $\mathrm{P}_{0}$ & $4.44 \mathrm{E} 6 \mathrm{~Pa}$ \\
\hline Van Genuchten $\mathrm{m}$ & 0.247 \\
\hline Residual liquid saturation, $\mathrm{S}_{\mathrm{lr}}$ & 0.18 \\
\hline Saturated liquid saturation, $\mathrm{S}_{\mathrm{ls}}$ & 1.0 \\
\hline $\begin{array}{l}\text { Residual gas saturation, } \mathrm{S}_{\mathrm{gr}} \text { for } \\
\text { Corey gas relative permeability }\end{array}$ & 0.0 \\
\hline Rock grain density, $\rho$ & $2,530 \mathrm{~kg} / \mathrm{m} 3$ \\
\hline Rock grain specific heat & $953 \mathrm{~J} / \mathrm{kg} \mathrm{K})$ \\
\hline Dry thermal conductivity & $1.67 \mathrm{~W} / \mathrm{m} \mathrm{K}$ \\
\hline Wet thermal conductivity & $2.0 \mathrm{~W} / \mathrm{m} \mathrm{K}$ \\
\hline Fracture Hydrological Properties \\
\hline Permeability, $\mathrm{k}$ & $1.00 \mathrm{E}-13 \mathrm{~m}{ }^{2}$ \\
\hline Porosity & $0.263 \mathrm{E}-3$ \\
\hline Van Genuchten, $\mathrm{P}_{0}$ & $1.027 \mathrm{E} 4 \mathrm{~Pa}$ \\
\hline Van Genuchten m & 0.492 \\
\hline Residual liquid saturation, $\mathrm{S}_{\mathrm{lr}}$ & 0.01 \\
\hline Saturated liquid saturation, $\mathrm{S}_{\mathrm{ls}}$ & 1.0 \\
\hline $\begin{array}{l}\text { Residual gas saturation, } \mathrm{S}_{\mathrm{gr}}, \text { for } \\
\text { Corey gas relative permeability }\end{array}$ & 0.0 \\
\hline $\begin{array}{l}\text { Fracture spacing for fracture- } \\
\text { matrix hydrologic interactions }\end{array}$ & $0.23 \mathrm{~m}$ \\
\hline Rock Mass Mechanical Properties \\
\hline Young's Modulus & $14.77 \mathrm{GPa}$ \\
\hline Poisson's ratio & 0.21 \\
\hline Thermal Expan. Coeff. & $5+0.0583 \times \mathrm{T} 10^{-6} /{ }^{\circ} \mathrm{C}$ \\
\hline
\end{tabular}


Table 2. Initial conditions

\begin{tabular}{|l|l|}
\hline Parameter & $\begin{array}{l}\text { Approximate value } \\
\text { at the level of DST }\end{array}$ \\
\hline \hline Vertical stress, $\sigma_{\mathrm{zi}}$ & $\approx 5.7 \mathrm{MPa}$ \\
\hline Min horizontal stress, $\sigma_{\mathrm{yi}}$ & $\approx 2.9 \mathrm{MPa}$ \\
\hline Max horizontal stress, $\sigma_{\mathrm{xi}}$ & $\approx 3.4 \mathrm{MPa}$ \\
\hline Initial temperature, $\mathrm{T}_{\mathrm{I}}$ & $\approx 24^{\circ} \mathrm{C}$ \\
\hline Initial Fracture saturation & $\approx 9 \%$ \\
\hline Initial matrix saturation & $\approx 90 \%$ \\
\hline Initial gas pressure & $\approx 0.9 \mathrm{bar}$ \\
\hline
\end{tabular}

${ }^{1}$ Approximate values of the depth-dependent parameters at the drift level.

Table 3. Boundary conditions

\begin{tabular}{|l|l|l|}
\hline \multicolumn{1}{|c|}{ Top boundary } & \multicolumn{1}{c|}{ Bottom boundary } & \multicolumn{1}{c|}{ Lateral boundaries } \\
\hline$T=22.8^{\circ} \mathrm{C}$ & $T=28.0^{\circ} \mathrm{C}$ & $\sigma_{x}=\sigma_{H}=\sigma_{v} \cdot 0.6=[3.61+2,200 \cdot 9.81 \cdot(\mathrm{z}-100)] \cdot 0.6 \mathrm{MPa}$ \\
$\sigma_{z}=\sigma_{v}=3.61 \mathrm{MPa}$ & $P_{g}=0.085 \mathrm{MPa}$ & $q_{w x}=0$ \\
$P_{g}=0.085 \mathrm{MPa}$ & $\mathrm{U}_{z}=0$ & $q_{t x}=0$
\end{tabular}




\section{List of Figure Captions}

Figure 1. The Yucca Mountain Drift Scale Test: (a) Layout and approximate measured extent of the boiling isotherm $\left(96^{\circ} \mathrm{C}\right.$ ) after four years of heating; (b) Evolution of heat power (total power in drift and wing heaters) and measured drift-wall temperature at a point located at the top of the drift about $10 \mathrm{~cm}$ into the rock.

Figure 2. The location of borehole cluster and 46 packed off intervals for measurement intervals for pneumatic (air-injection) tests and test results: (a) Horizontal view indicating the locations of the three borehole clusters along the Heated Drift. (b, c, d) Vertical cross sections at each borehole cluster showing the exact location of each measurement interval, with solid thick line indicating the extent of each section and open circles indicating their center points. (e) Test results in terms of a permeability change factor $\left(\mathrm{k} / \mathrm{k}_{\mathrm{i}}\right)$ derived from more than 700 airinjection tests in 44 sections over eight years of heating and cooling.

Figure 3. TOUGH-FLAC simulation of the DST: (a) Two-dimensional model geometry; (b) conceptual model for stress-permeability coupling; (c) normal stress versus aperture relationship for fractures.

Figure 4. Comparison of measured and simulated temperature evolution: (a) Evolution of drift-wall temperature, indicating the effect of out-of-plane heat loss; (b) Comparison of temperature profiles along a vertical borehole emanating from the top of the drift. The measured results are taken from a vertical borehole located at $\mathrm{Y}=22.8 \mathrm{~m}$ (i.e., near the center of the Heated Drift).

Figure 5. Calculated temperature contours at the end of the four-year heating period (a) and at the end of the subsequent four-year cooling period (b).

Figure 6. Calculated changes in liquid saturation in the fractured continuum as a result of thermally driven vaporization and condensation process: (a) At the end of the four-year heating period and (b) at the end of the subsequent four-year cooling period.

Figure 7. Calculated changes in horizontal stress, equivalent to changes in stress normal to drift-parallel vertical fractures: (a) At the end of the four-year heating period and (b) at the end of the subsequent four-year cooling period.

Figure 8a. Comparison of calculated (solid line for TM and dashed line for THM) and measured (symbols) permeability change factor $\mathrm{k} / \mathrm{ki}$ in borehole cluster 57-to-61, located at $\mathrm{y}$ $=10 \mathrm{~m}$. See Figure 2 for location of each test interval.

Figure 8b. Comparison of calculated (solid line for TM and dashed line for THM) and measured (symbols) permeability change factor $\mathrm{k} / \mathrm{ki}$ in borehole cluster 74-to-78, located at $\mathrm{y}$ $=30 \mathrm{~m}$. See Figure 2 for location of each test interval. 
Figure 8c. Comparison of calculated (solid line for TM and dashed line for THM) and measured (symbols) permeability change factor $\mathrm{k} / \mathrm{k}_{\mathrm{i}}$ in borehole cluster 185 -to-186, located at $\mathrm{y}=44 \mathrm{~m}$. See Figure 2 for location of each test interval.

Figure 9. Results from two test intervals in which stress- and moisture-induced changes can be clearly distinguished by the modeling: (a) Results at test interval 76:4, in which the model simulation shows that both TM and TH processes impact the measured evolution in the permeability change factor; and (b) results at test interval 57:1, in which the model simulation shows that the measured evolution in the permeability change factor is caused solely by TM changes.

Figure 10. Composite plots illustrating the overall match between measured and calculated permeability change factors, including data from over 700 air-injection tests: (a) Calculated stress normal to vertical fractures as a function of both measured and calculated permeability change factor caused by stress-induced change in fracture aperture, (b) calculated gas saturation in the fracture system as a function of both measured and calculated permeability change factor caused by moisture-induced changes in gas relative permeability; and (c) measured versus calculated permeability change factor considering both stress- and moistureinduced changes.

Figure 11. Composite plot for the evolution of the measured and calculated permeability change factors at 11 test intervals $(57: 1,57: 2,58: 1,74: 1,74: 2,75: 1,75: 2,76: 1,185: 1,185: 3$, 186:1) where interpretable air-permeability data could be retrieved for the entire eight-year heating and cooling cycle. 


\section{Figures}

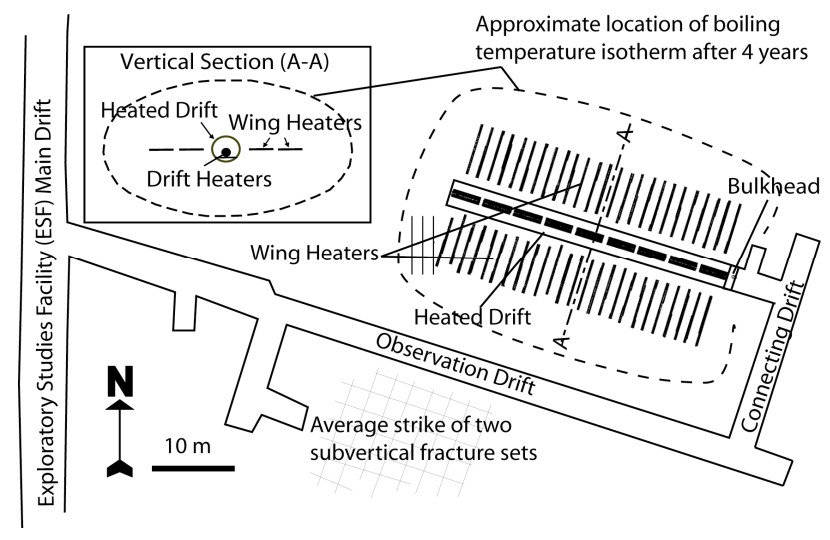

(a)

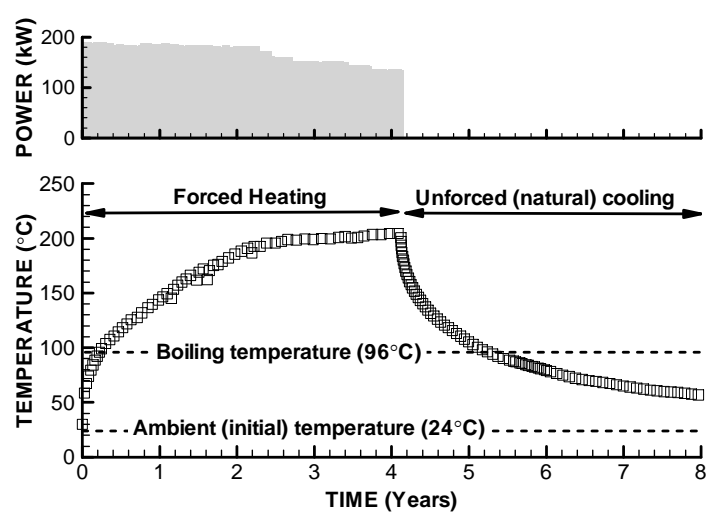

(b)

Figure 1. The Yucca Mountain Drift Scale Test: (a) Layout and approximate measured extent of the boiling isotherm $\left(96^{\circ} \mathrm{C}\right.$ ) after four years of heating; (b) Evolution of heat power (total power in drift and wing heaters) and measured drift-wall temperature at a point located at the top of the drift about $10 \mathrm{~cm}$ into the rock. 


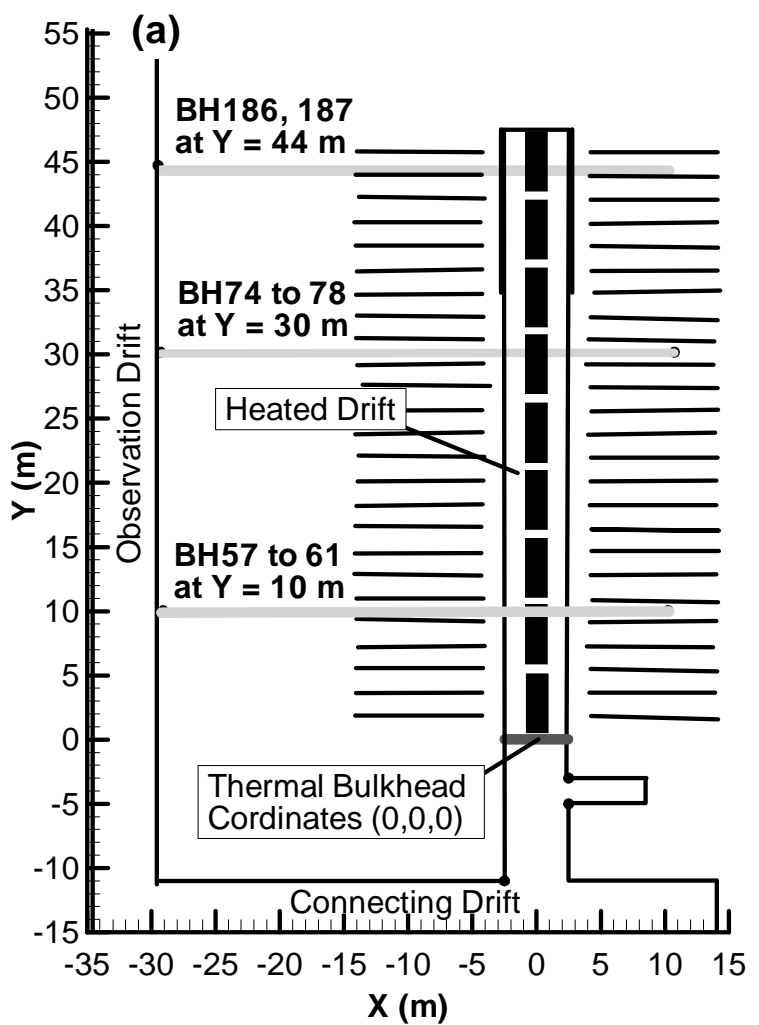

(e)

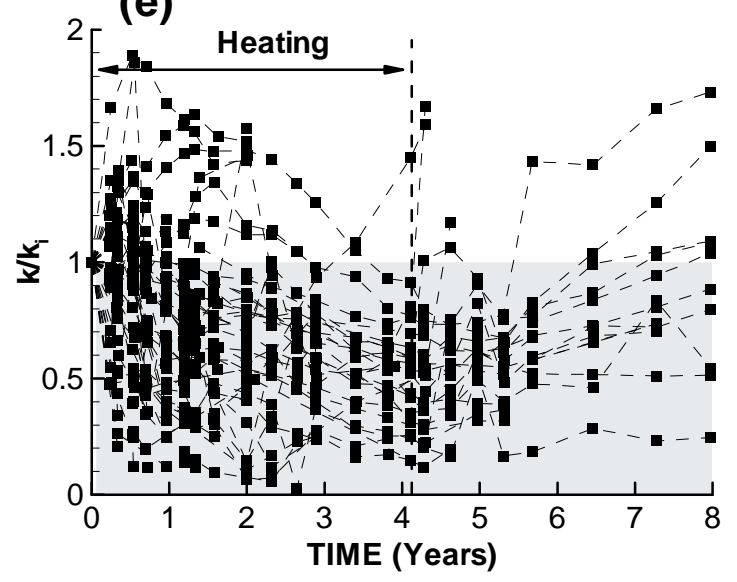

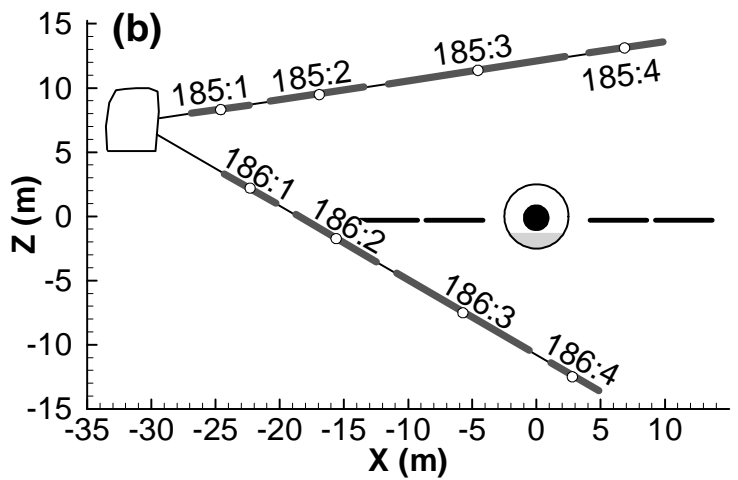
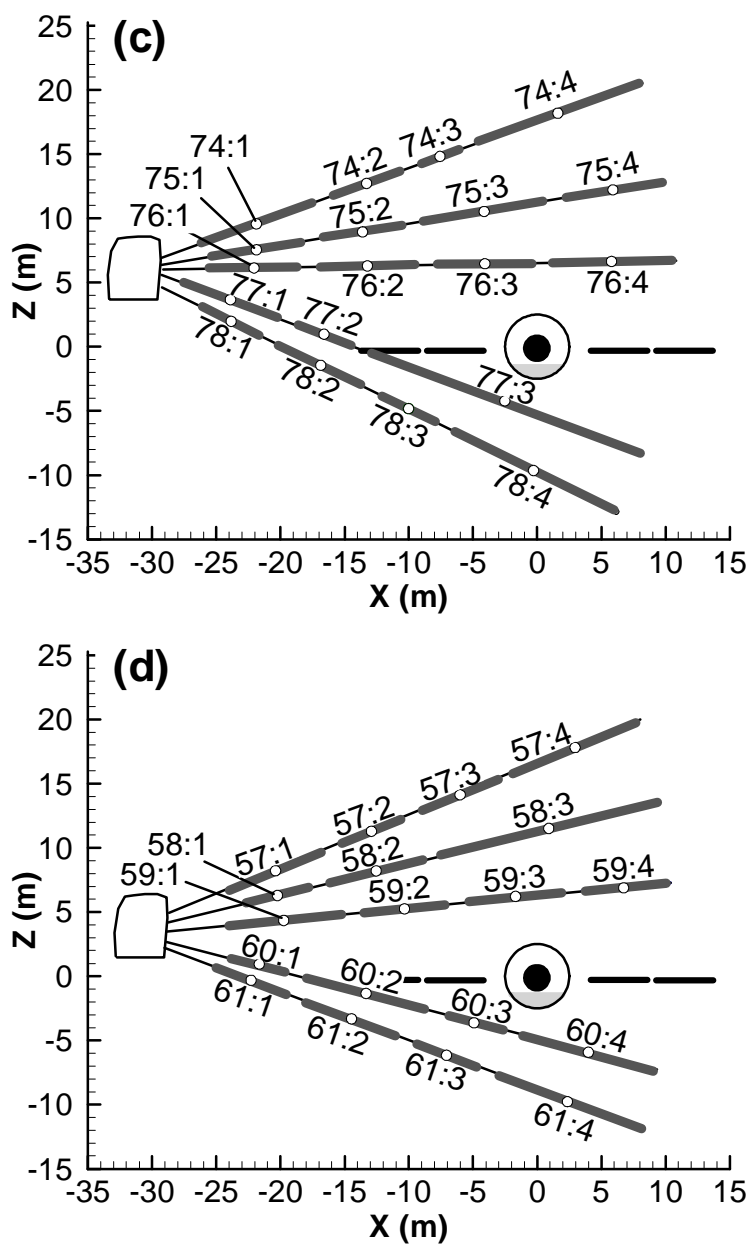

Figure 2. The location of borehole cluster and 46 packed off intervals for measurement intervals for pneumatic (air-injection) tests and test results: (a) Horizontal view indicating the locations of the three borehole clusters along the Heated Drift. (b, c, d) Vertical cross sections at each borehole cluster showing the exact location of each measurement interval, with solid thick line indicating the extent of each section and open circles indicating their center points. (e) Test results in terms of a permeability change factor $\left(\mathrm{k} / \mathrm{k}_{\mathrm{i}}\right)$ derived from more than 700 air-injection tests in 44 sections over eight years of heating and cooling. 


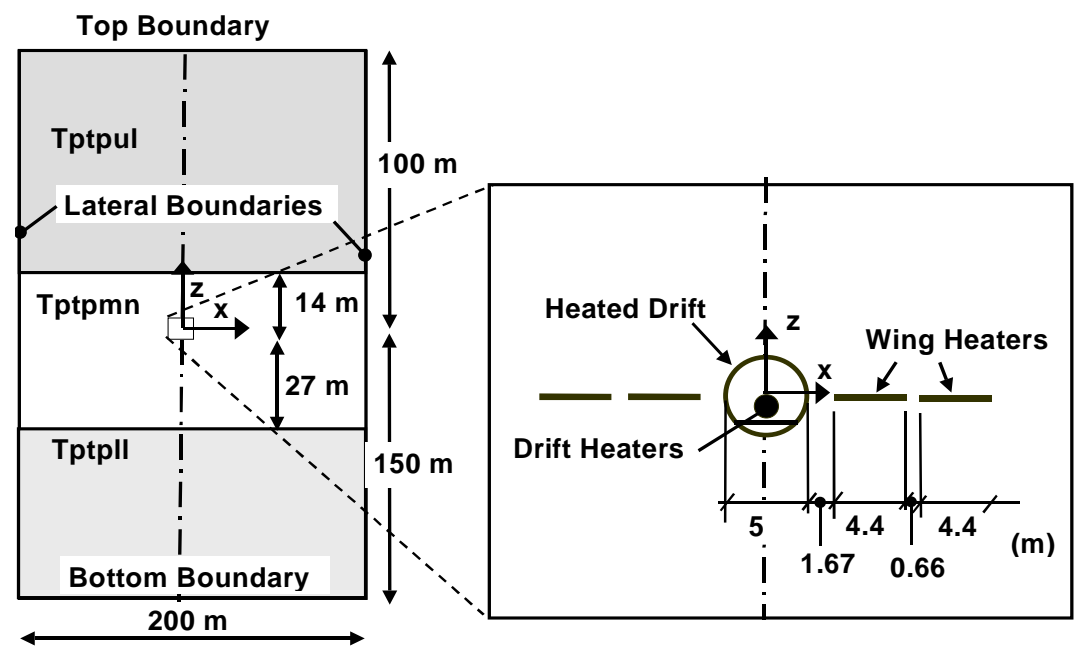

(a)

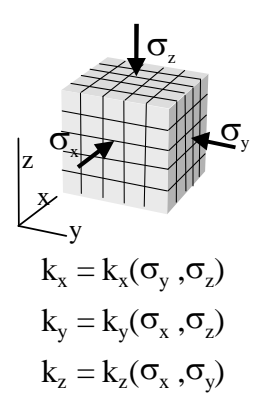

(b)

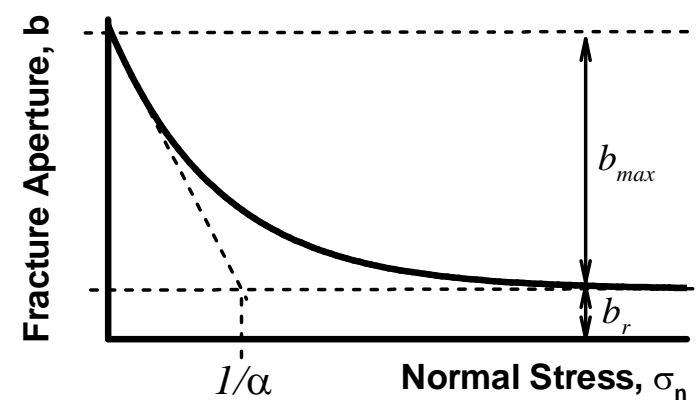

(c)

Figure 3. TOUGH-FLAC simulation of the DST: (a) Two-dimensional model geometry; (b) conceptual model for stress-permeability coupling; (c) normal stress versus aperture relationship for fractures. 


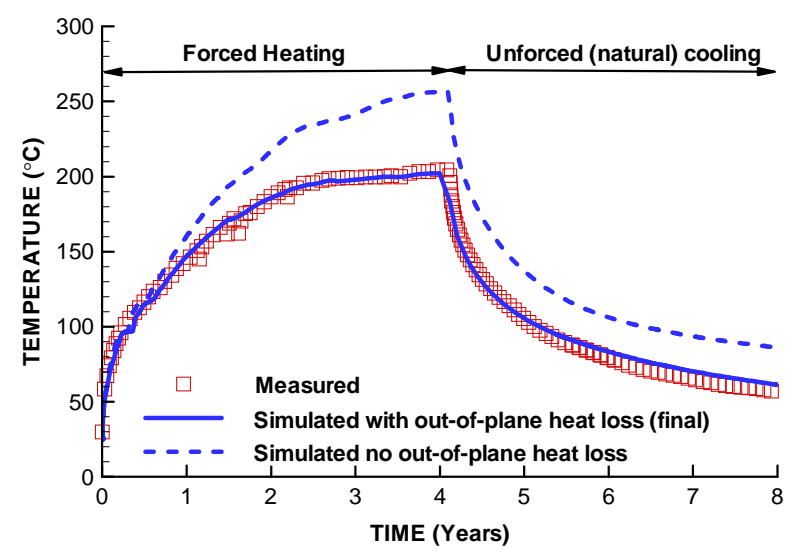

(a)

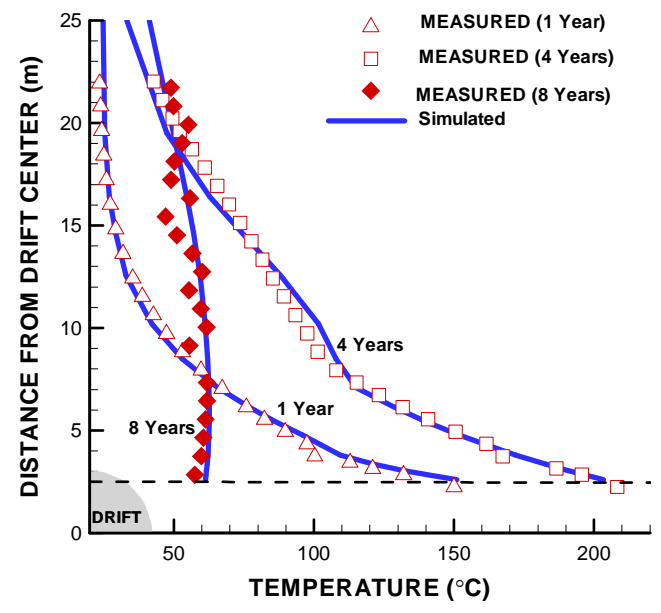

(b)

Figure 4. Comparison of measured and simulated temperature evolution: (a) Evolution of drift-wall temperature, indicating the effect of out-of-plane heat loss; (b) Comparison of temperature profiles along a vertical borehole emanating from the top of the drift. The measured results are taken from a vertical borehole located at $\mathrm{Y}=22.8 \mathrm{~m}$ (i.e., near the center of the Heated Drift). 


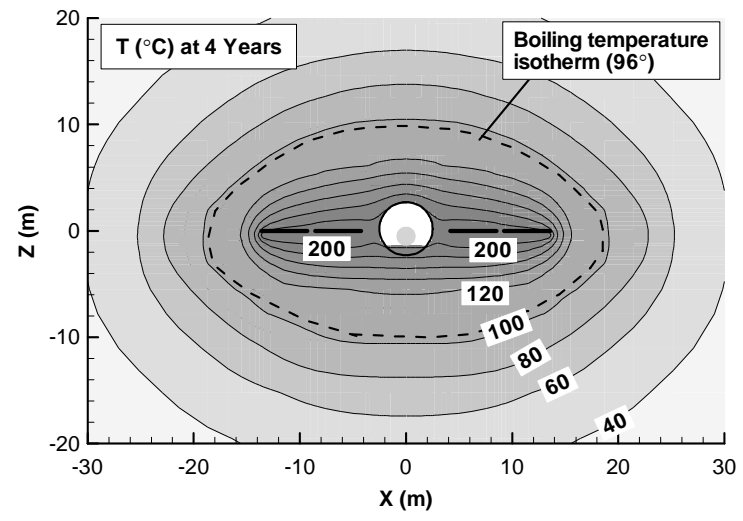

(a)

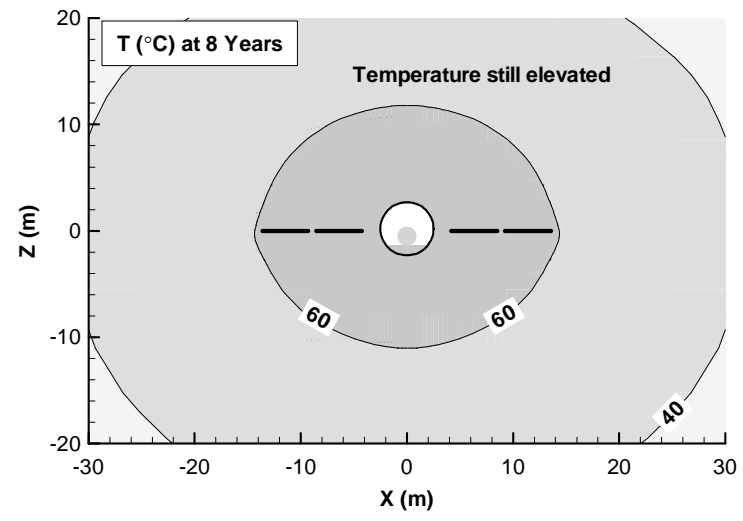

(b)

Figure 5. Calculated temperature contours at the end of the four-year heating period (a) and at the end of the subsequent four-year cooling period (b). 


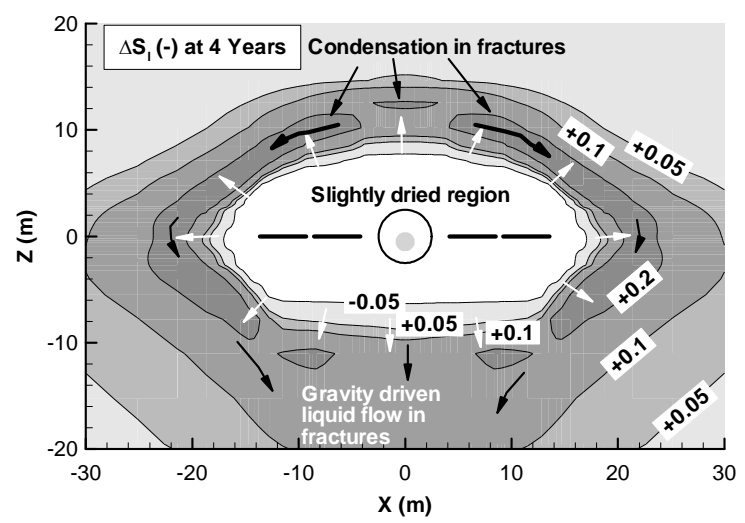

(a)

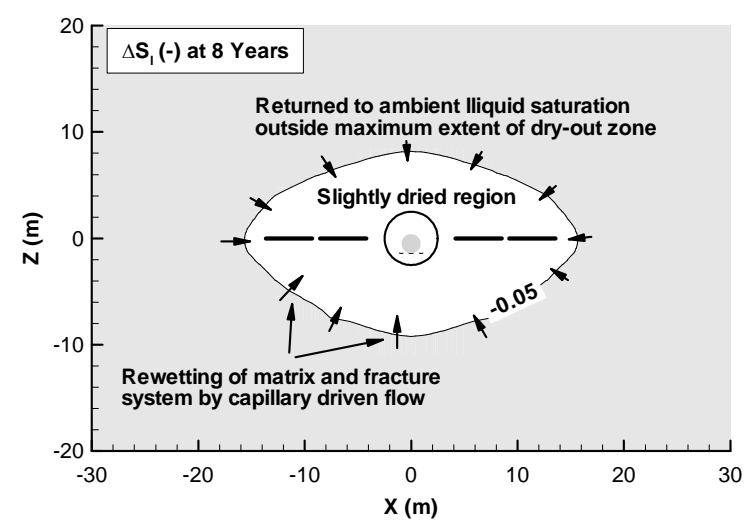

(b)

Figure 6. Calculated changes in liquid saturation in the fractured continuum as a result of thermally driven vaporization and condensation process: (a) At the end of the four-year heating period and (b) at the end of the subsequent four-year cooling period. 


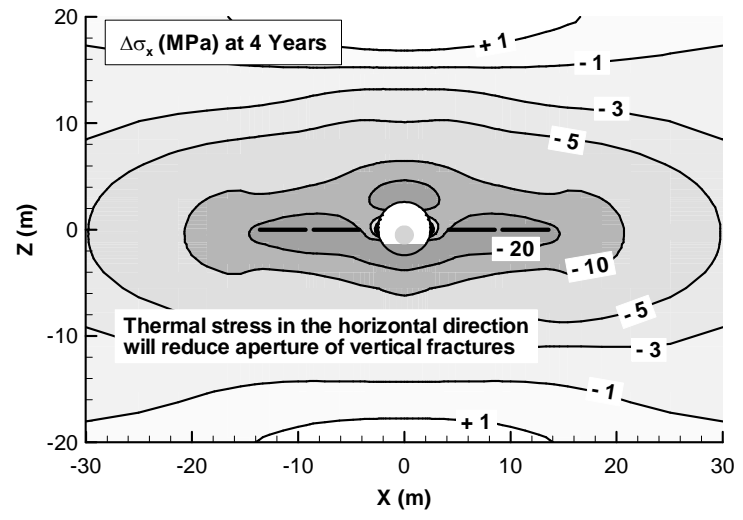

(a)

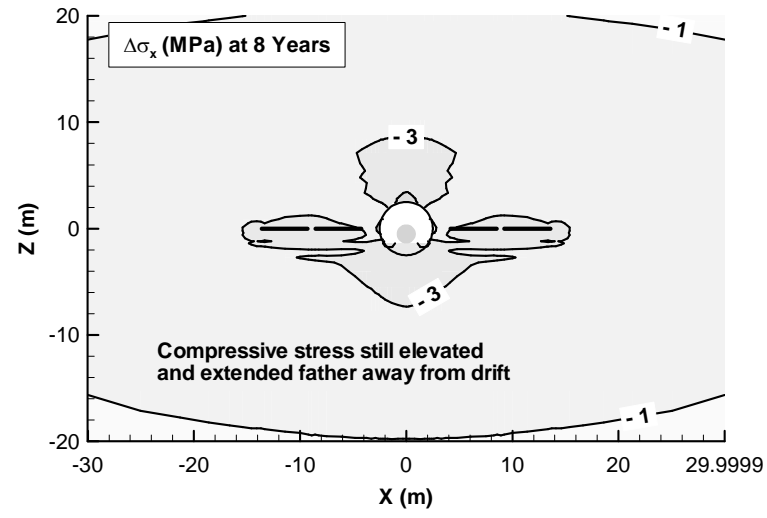

(b)

Figure 7. Calculated changes in horizontal stress, equivalent to changes in stress normal to drift-parallel vertical fractures: (a) At the end of the four-year heating period and (b) at the end of the subsequent four-year cooling period. 

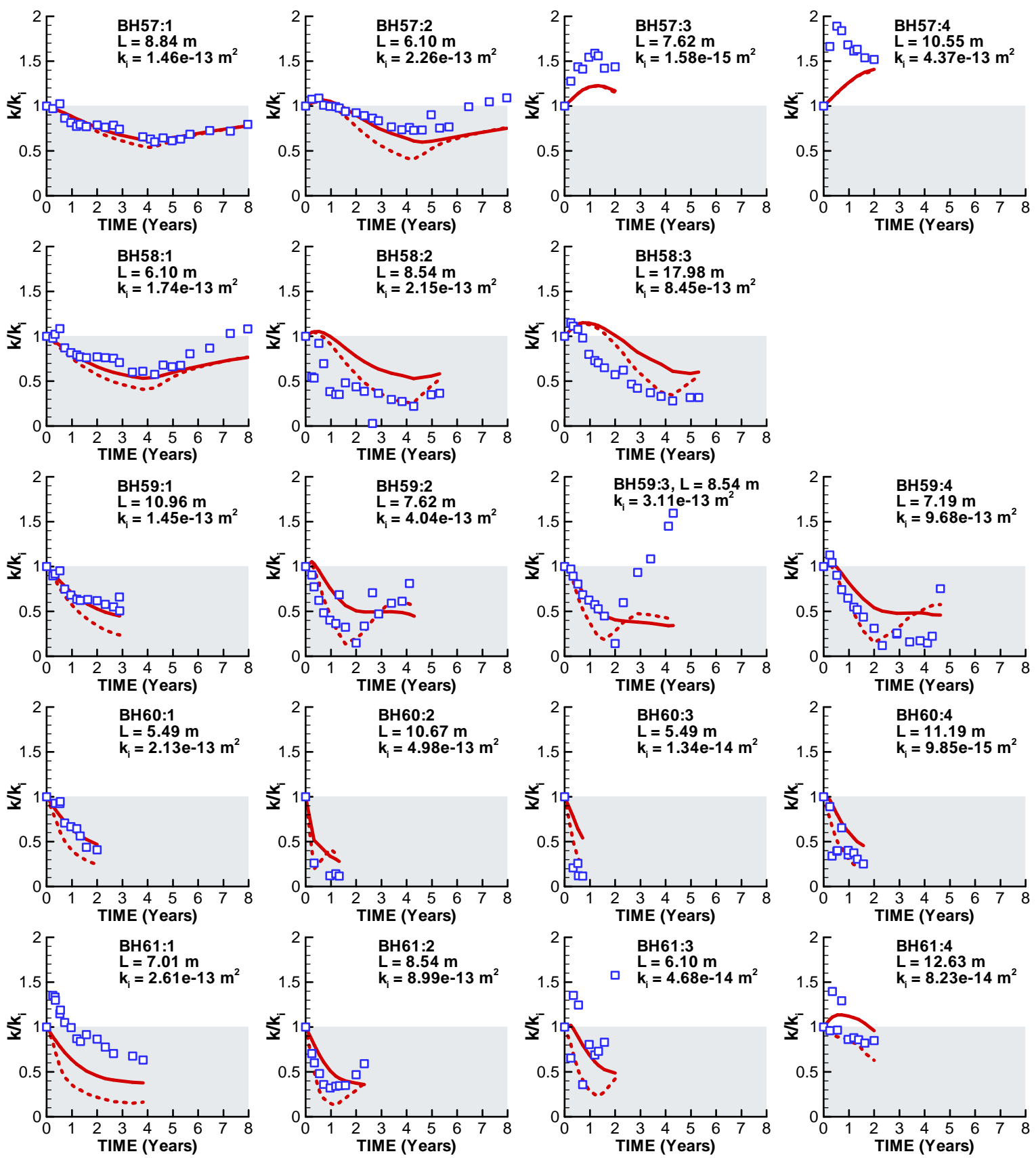

Figure 8a. Comparison of calculated (solid line for TM and dashed line for THM) and measured (symbols) permeability change factor $\mathrm{k} / \mathrm{k}_{\mathrm{i}}$ in borehole cluster 57 -to-61, located at $\mathrm{y}$ $=10 \mathrm{~m}$. See Figure 2 for location of each test interval. 

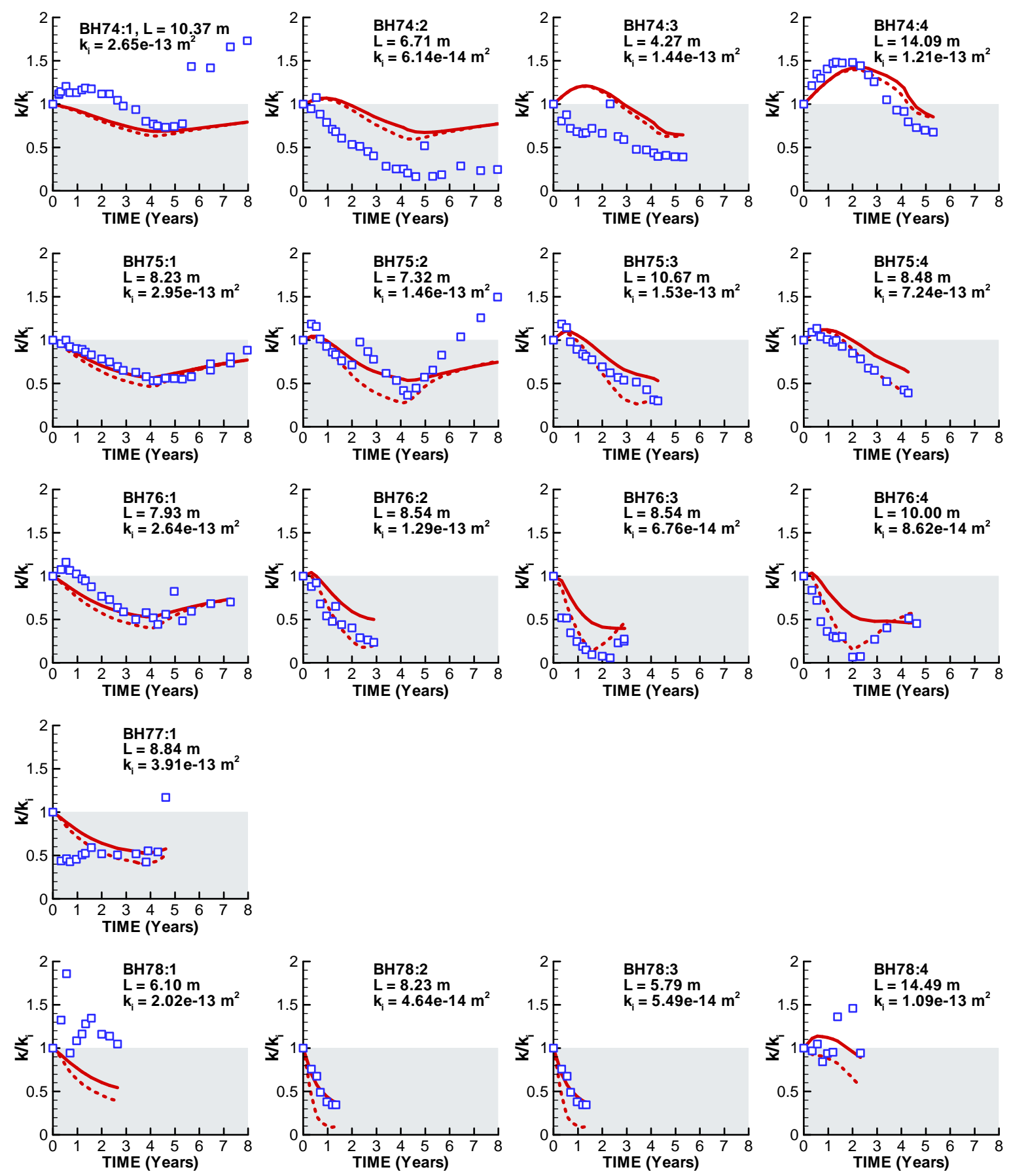

Figure 8b. Comparison of calculated (solid line for TM and dashed line for THM) and measured (symbols) permeability change factor $\mathrm{k} / \mathrm{k}_{\mathrm{i}}$ in borehole cluster 74 -to-78, located at $\mathrm{y}$ $=30 \mathrm{~m}$. See Figure 2 for location of each test interval. 

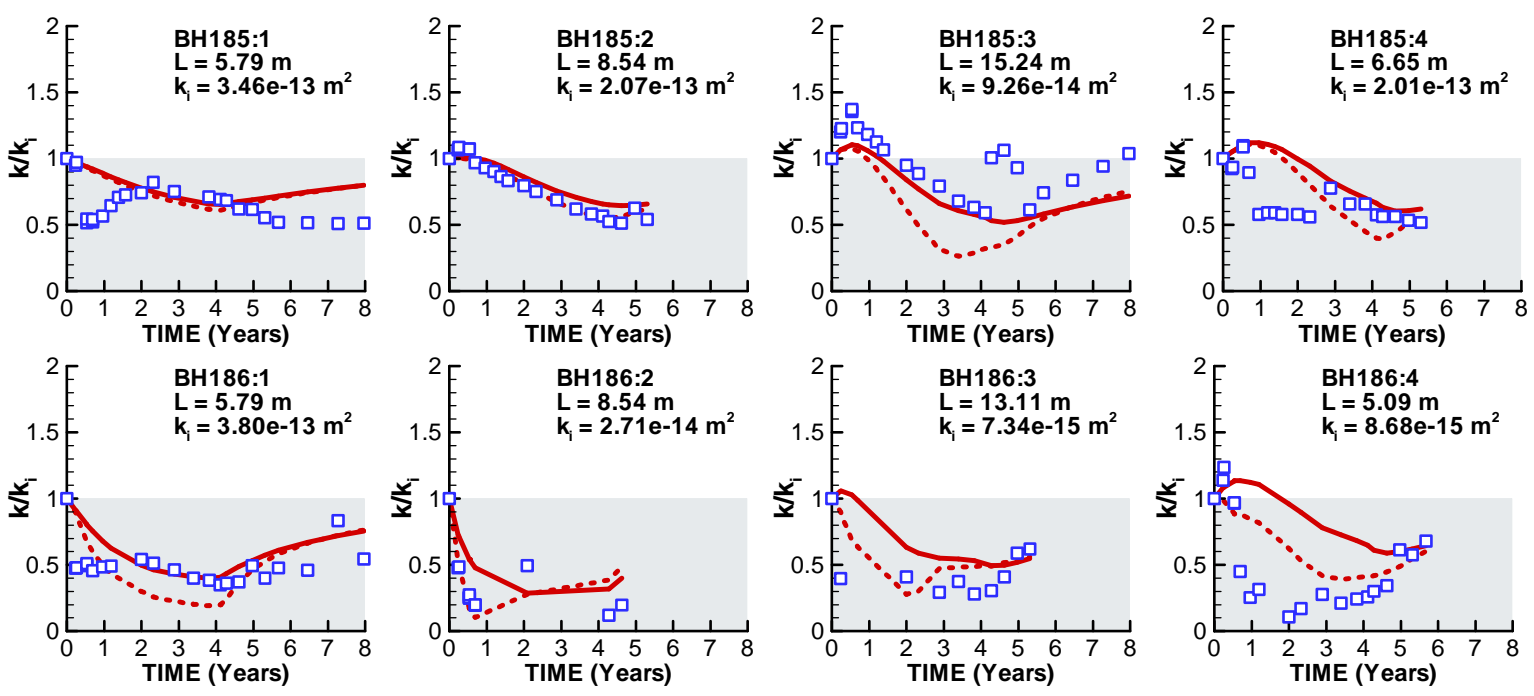

Figure 8c. Comparison of calculated (solid line for TM and dashed line for THM) and measured (symbols) permeability change factor $\mathrm{k} / \mathrm{k}_{\mathrm{i}}$ in borehole cluster 185 -to-186, located at $y=44 \mathrm{~m}$. See Figure 2 for location of each test interval. 


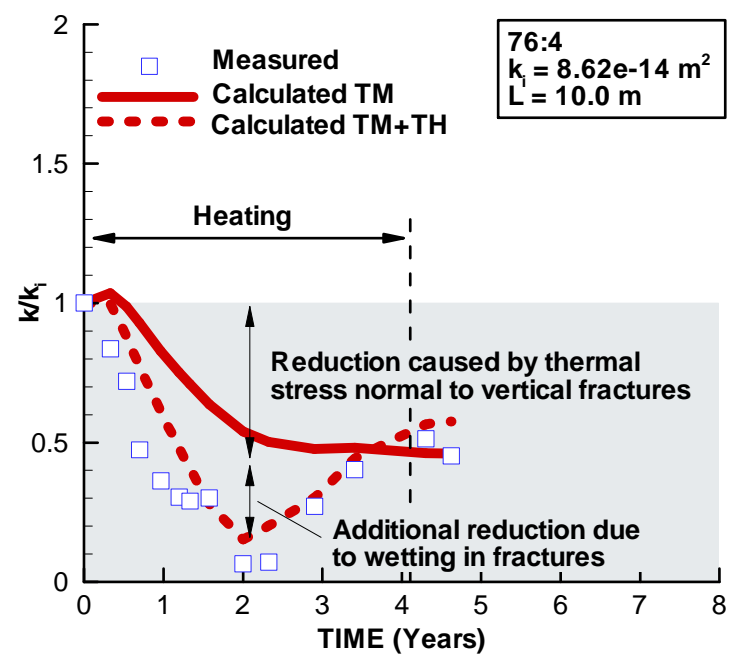

(a)

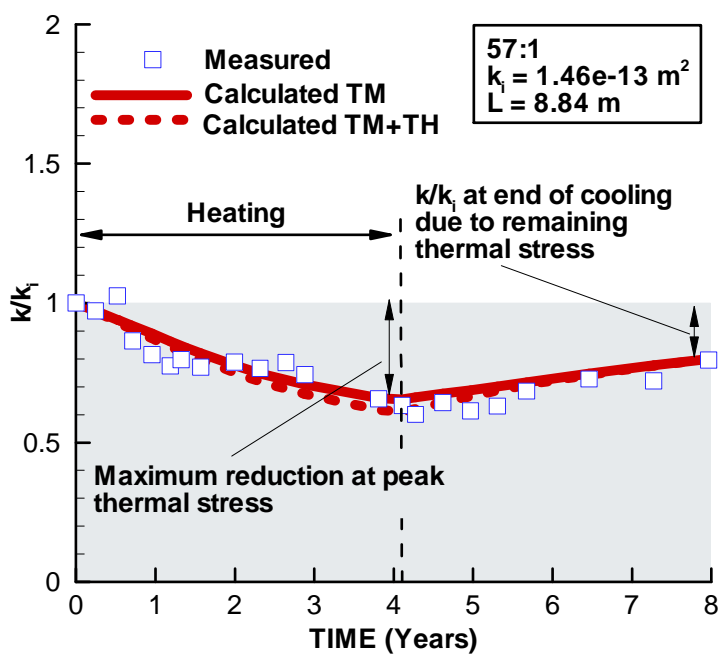

(b)

Figure 9. Results from two test intervals in which stress- and moisture-induced changes can be clearly distinguished by the modeling: (a) Results at test interval 76:4, in which the model simulation shows that both TM and TH processes impact the measured evolution in the permeability change factor; and (b) results at test interval 57:1, in which the model simulation shows that the measured evolution in the permeability change factor is caused solely by TM changes. 


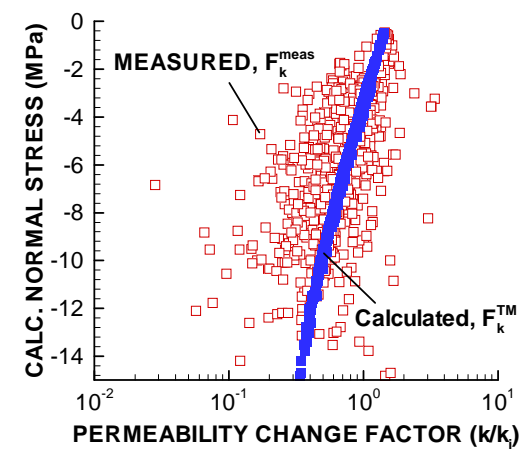

(a)

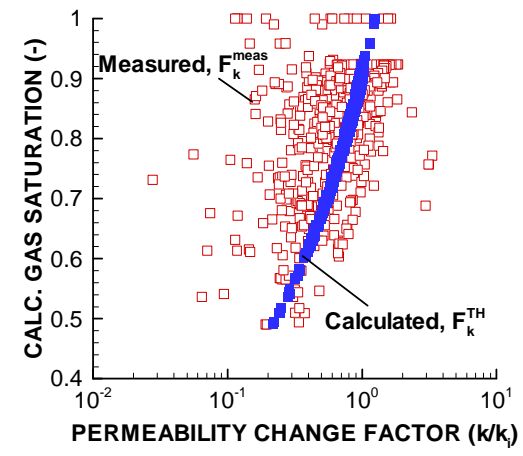

(b)

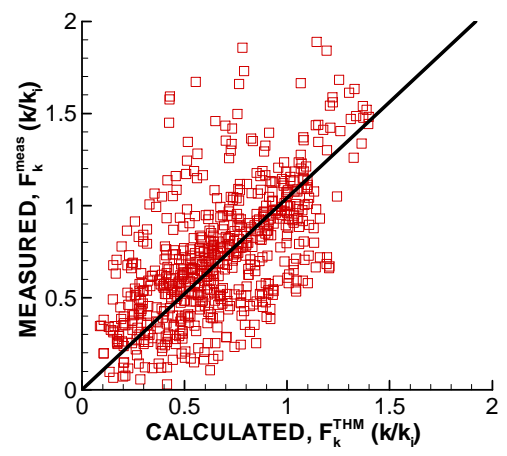

(c)

Figure 10. Composite plots illustrating the overall match between measured and calculated permeability change factors, including data from over 700 air-injection tests: (a) Calculated stress normal to vertical fractures as a function of both measured and calculated permeability change factor caused by stress-induced change in fracture aperture, (b) calculated gas saturation in the fracture system as a function of both measured and calculated permeability change factor caused by moisture-induced changes in gas relative permeability; and (c) measured versus calculated permeability change factor considering both stress- and moistureinduced changes. 


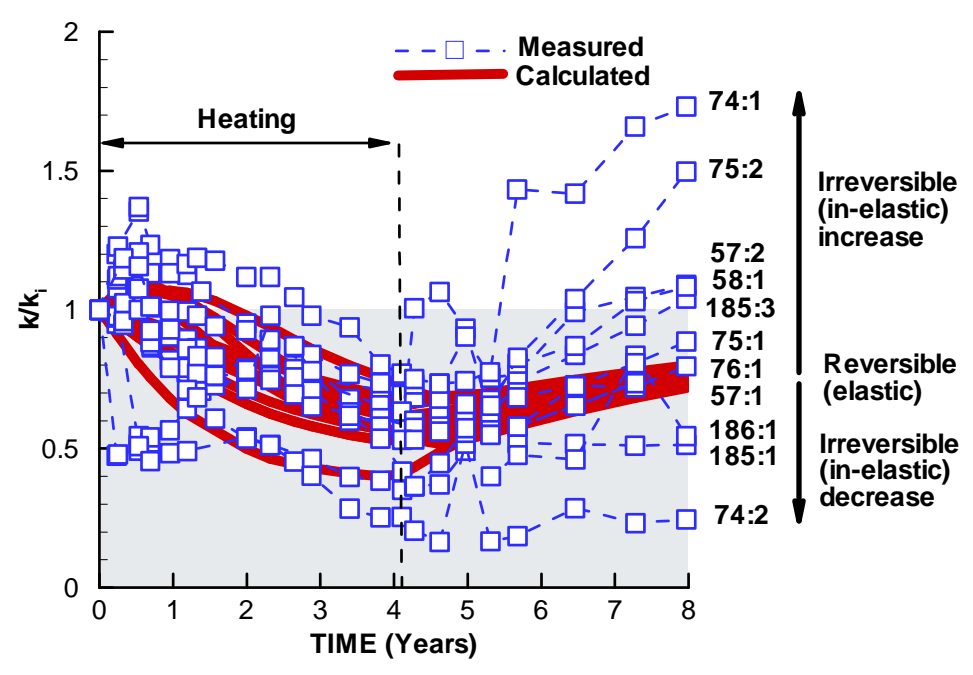

Figure 11. Composite plot for the evolution of the measured and calculated permeability change factors at 11 test intervals $(57: 1,57: 2,58: 1,74: 1,74: 2,75: 1,75: 2,76: 1,185: 1,185: 3$, 186:1) where interpretable air-permeability data could be retrieved for the entire eight-year heating and cooling cycle. 